\title{
Temperatures, heating rates and vapour pressures in near-surface snow at the South Pole
}

\author{
Michael S. TOWN, ${ }^{1}$ Edwin D. WADDINGTON, ${ }^{2}$ Von P. WALDEN, ${ }^{3}$ \\ Stephen G. WARREN ${ }^{1,2}$ \\ ${ }^{1}$ Department of Atmospheric Sciences, University of Washington, Seattle, Washington 98195-1640, USA \\ E-mail: mstown@atmos.washington.edu \\ ${ }^{2}$ Department of Earth and Space Sciences, University of Washington, Seattle, Washington 98195-1310, USA \\ ${ }^{3}$ Department of Geography, University of Idaho, Moscow, Idaho 83844-3021, USA
}

\begin{abstract}
A finite-volume model is used to simulate 9 years (1995-2003) of snow temperatures at the South Pole. The upper boundary condition is skin-surface temperature derived from routine upwelling longwave radiation measurements, while the lower boundary condition is set to the seasonal temperature gradient at $6.5 \mathrm{~m}$ depth, taken from prior measurements at the South Pole. We focus on statistics of temperature, heat fluxes, heating rates and vapour pressures in the top metre of snow, but present results from the full depth of the model $(6.5 \mathrm{~m})$. The monthly mean net heat flux into the snow agrees with results from previous studies performed at the South Pole. On shorter timescales, the heating rates and vapour pressures show large variability. The net heat flux into the snow, which is between $\pm 5 \mathrm{~W} \mathrm{~m}^{-2}$ in the monthly mean, can be greater than $\pm 20 \mathrm{~W} \mathrm{~m}^{-2}$ on hourly timescales. On sub-daily timescales, heating rates exceed $40 \mathrm{~K} \mathrm{~d}^{-1}$ in the top $10 \mathrm{~cm}$ of the snow. Subsurface temperatures, and therefore heating rates, are more variable during winter (April-September) due to increased synoptic activity and the presence of a strong, surface-based, atmospheric temperature inversion. The largest vapour pressures $(60-70 \mathrm{~Pa})$ and vertical gradients of vapour pressure are found in the top metre of snow during the short summer (December-January). In contrast, during the long winter, the low temperatures result in very small vapour pressures and insignificant vapour-pressure gradients. The high summertime vapour-pressure gradients may be important in altering the isotopic composition of snow and ice on the Antarctic plateau.
\end{abstract}

\section{INTRODUCTION}

Antarctic snow and firn have been the subject of numerous studies to understand the present-day climate and atmospheric composition of Antarctica, and to reconstruct past local, regional and global Antarctic climate (e.g. Dalrymple and others, 1966; McConnell and others, 1998; MosleyThompson and others, 1999; Stauffer and others, 2004; Mayewski and others, 2005; Kawamura and others, 2006; Helmig and others, 2007). The snow surface plays a unique role in Antarctic climate. Its high albedo and high infrared emissivity often lead to surface-based atmospheric temperature inversions. Physically porous and optically transmissive, the snow is a site of significant heterogeneous photochemistry. The snow surface is a good insulator (Trenberth, 1983). However, enough energy is stored in the snow and released to the atmosphere to affect surface atmospheric temperatures on all timescales. Atmospheric energy is commuted to the snow through conduction, transport as water vapour or sensible heat through pore spaces, or 'advection' (i.e. burial by subsequent accumulation). The stored energy from summer is then gradually released to the atmosphere during the long winter. The magnitude of the net heat flux into snow or reflux (i.e. the degree to which the snow acts as an energy capacitor) depends on both the time and depth scale of interest.

Energy transfer within Antarctic snow is often presented as part of surface energy-balance investigations. It is estimated through in situ measurements of snow temperatures (e.g. Dalrymple and others, 1966; Carroll, 1982; Jackson, 1982; Brandt and Warren, 1993, 1997), by modelling heat transfer in the snow (e.g. King and others, 1996; King and Connolley, 1997; Bintanja, 2000; Reijmer and Oerlemans, 2002; Van As and others, 2005; Van den Broeke and others, $2005,2006)$, or as a residual of all other components in the surface energy balance (e.g. Bailey and Lynch, 2000). These studies show that the net heat flux into snow, the sum of the radiative and turbulent heat fluxes at the snow surface $(G)$, is usually small in the monthly mean in Antarctica. The net heat fluxes into the snow are on the order of a few $\mathrm{W} \mathrm{m}^{-2}$, regardless of latitude, longitude, altitude or continentality, when compared to monthly means of other components of the surface energy balance. For example, the monthly mean net radiation fluxes at Pionerskaya, East Antarctica, $\left(70^{\circ} \mathrm{S}, 95^{\circ} \mathrm{E} ; 2700 \mathrm{~m}\right.$ a.s.l.) during December and June are $24 \mathrm{~W} \mathrm{~m}^{-2}$ and $-28 \mathrm{Wm}^{-2}$, respectively, approximately four times greater than the net heat fluxes into snow during those months. The monthly mean individual radiation components are 25-60 times greater than the monthly mean net heat flux into snow (Warren, 1996).

However, some studies have shown that the net heat flux into snow is much larger on timescales shorter than 1 month, due to large and rapid changes in near-surface snow temperatures (e.g. Carroll, 1982; King and others, 1996; McConnell and others, 1998; Bintanja, 2000; Reijmer and Oerlemans, 2002; Van As and others, 2005; Van den Broeke and others, 2006). Surface temperatures in Antarctica are particularly sensitive to changes in atmospheric conditions (i.e. 
atmospheric temperature, surface wind speed and cloud cover) during winter due to the existence of a surface-based atmospheric temperature inversion.

These studies highlight the importance of near-surface snow temperatures and net heat fluxes in the surface energy balance, which is important to a broad range of polar sciences such as weather and climate prediction, atmospheric chemistry and paleoclimatology. Operational and researchoriented models of polar climate and polar weather rely on accurate simulations of the surface energy balance to predict near-surface atmospheric temperatures. Unfortunately, heat fluxes into snow are sometimes neglected, or tuned to correct for other errors within these complex simulations. Inaccurate net heat fluxes into snow can feed back harmfully on other components of the surface energy balance in such simulations (e.g. Hines and others, 1999). Large temperature gradients in the near-surface snow may cause heterogeneous migration of trace chemical species within the snow (personal communication from D. Davis, 2007). There is also evidence that large, short-term changes in near-surface snow temperatures, and therefore in pore-space vapour pressures, can affect the water stable-isotopic content of near-surface snow (Town, 2007).

Despite awareness of the high snow-temperature and heat-flux variability in response to changing atmospheric conditions, there have been only a few systematic characterizations of these short-term processes. Bintanja (2000), Van As and others (2005) and Van den Broeke and others (2006) characterized the mean diurnal variability of the surface energy balance during summer in Dronning Maud Land, Antarctica. The mean influence of clouds on the diurnal surface energy-balance cycle from the coast to the East Antarctic plateau was further examined by Van den Broeke and others (2006). Many of the studies listed above are seasonal and/or limited to 1-3 years in duration. Systematic characterization of snow temperature variability throughout an annual cycle and interannual variability of snow temperature has therefore not yet been reported for the East Antarctic plateau.

To extend the quantitative understanding of annual cycles in snow temperatures and heat fluxes in Antarctica to submonthly and interannual timescales, we present results from a one-dimensional (1-D) model of snow temperatures for 9 years at the South Pole. We have chosen the South Pole for this project for several reasons. It is a well-established research station with a high-quality, long-term climatological dataset collected by the US National Oceanic and Atmospheric Administration (NOAA) Earth and Space Research Laboratory - Global Monitoring Division (ESRL-GMD). The dataset is often used for testing polar climate and forecast models (e.g. King and Connolley, 1997; Briegleb and Bromwich, 1998; Hines and others, 2004; Fogt and Bromwich, in press). The South Pole is also the site of numerous experiments on heterogeneous chemistry (e.g. McConnell and others, 1998; Chen and others, 2004; Davis and 9 others, 2004; Hutterli and others, 2004), as well as the site of fundamental Antarctic climate studies (Dalrymple and others, 1966; Schwerdtfeger, 1970) and paleoclimate studies (e.g. Epstein and others, 1965; Aldaz and Deutsch, 1967; Jouzel and others, 1983). The short-term and interannual variability of snow temperatures and heat fluxes is important to each of these applications. Because of the small slope and spatial homogeneity of the East Antarctic plateau around the South Pole, results for this location can be extrapolated to represent a much larger region of similar slope, altitude and continentality.

\section{MODELLING NEAR-SURFACE SNOW AT THE SOUTH POLE}

We use a 1-D, finite-volume model of heat conduction and flow to simulate temperatures in the near-surface snow. Similar models have been used previously in Antarctica and Greenland (e.g. Greuell and Konzelmann, 1994; King and others, 1996; King and Connolley, 1997; Bintanja, 2000; Reijmer and Oerlemans, 2002; Liston and Winther, 2005; Van den Broeke and others, 2005, 2006).

Modelling snow temperature and heat flux in polar snow is often done as an alternative to in situ measurements because there are several challenges associated with direct measurements of snow temperature. In situ snow-temperature measurements may be biased by solar heating; temperature measurements are therefore most accurate during the polar night (Brandt and Warren, 1993, 1997). Accumulation will advect in situ probes away from the surface, so prolonged measurements of near-surface temperature and snow heat flux require frequent attention. Installation of thermistors or other probes also disturbs snowpack temperature and density, affecting measurements of snow temperature and estimates of the net heat flux into snow. Snow temperature has been measured directly at the South Pole on several occasions (Dalrymple and others, 1966; Carroll, 1982; Brandt and Warren, 1993, 1997).

Snow temperatures are generally modelled using one of two different upper boundary conditions. One can use the surface energy balance, atmospheric conditions and net heat fluxes into snow to determine snow temperatures (e.g. Greuell and Konzelmann, 1994; Bintanja, 2000; Reijmer and Oerlemans, 2002; Liston and Winther, 2005; Van den Broeke and others, 2005, 2006). In Antarctica, this methodology is most successful during the short summer (December-January) when the boundary layer is nearly isothermal, allowing accurate observation or estimation of both radiative and turbulent fluxes. Under the extremely stable conditions of the polar night, both quantities are less accurate. Inaccuracies in radiative and turbulent fluxes feed inaccuracies into estimates of net heat fluxes into snow, and ultimately into snow temperatures. Estimates of turbulent heat fluxes suffer more than radiative fluxes because current surface-layer parameterizations have trouble simulating the intermittency of turbulence in extremely stable boundary layers such as those found in Antarctica during winter (Mahrt, 1998; Pahlow and others, 2001; Cheng and others, 2005). In comparison, the radiative flux measurements are more straightforward, requiring attention primarily to simple environmental factors such as frost or blowing snow.

Alternatively, surface temperature can be used as an upper boundary condition to determine the heat flux into snow (e.g. King and others, 1996; King and Connolley, 1997). This methodology requires only an accurate estimate of skinsurface temperature, which is an effective integration of all the atmospheric energy fluxes into snow, with the exception of some subsurface absorption of solar radiation.

In both cases, simulations are limited by knowledge of snow properties (density, thermal conductivity and heat capacity). Over most of Antarctica there is no melting, so the net heat flux into snow can be modelled as a pure advectivediffusive process, described below. Exceptions are found 
mainly around the coast, in katabatic-wind zones and blueice areas (Bintanja, 2000; Liston and Winther, 2005). Depending on the timescales of interest, downward advection of heat (through accumulation) can also be neglected.

Our model is based on the finite-volume method described in Patankar (1980). In this section we describe relevant features of our model and the method of validation. We then show how the snow is parameterized, and describe the data used to simulate 9 years of near-surface snow temperatures.

\section{Finite-volume model}

The finite-volume model is based on the differential equation for heat conduction and advection:

$$
\frac{\partial}{\partial t}(T)+\frac{\partial}{\partial z}(b T)=\frac{1}{\rho C_{p}} \frac{\partial}{\partial z}\left(k \frac{\partial}{\partial z} T\right)+\frac{S}{\rho C_{p}},
$$

where $T$ is temperature, $b$ is the advection rate (in this application it is the snow accumulation rate), $k$ is the thermal conductivity, $\rho$ is the snow density and $C_{p}$ is the heat capacity. $k / \rho C_{p}$ is the snow thermal diffusivity. $S$ is the source term, to be described below.

This formulation comes from an advective-diffusive equation for enthalpy (Patankar, 1980). The equation is applicable to any quantity that is subject to diffusion under a gradient or advection under fluid flow. Each term in Equation (1) has units $\mathrm{Ks}^{-1}$. The boundaries of the $1-\mathrm{D}$ solution domain are fixed at the snow surface and at a specified depth.

In our case, the uppermost boundary is the transient surface (i.e. it is fixed with respect to the snow surface regardless of the accumulation rate $b$ ). When significant accumulation is incorporated into the model, snow of a given $T$ is pushed (advected) downward relative to the upper boundary of the model. On the righthand side of Equation (1), the first term represents the diffusion of heat down a temperature gradient. The second term on the righthand side, the source term, accounts for any process that may change the temperature of a control volume but is not related to the processes of thermal diffusion or advection. One potential source-term process is absorption of solar radiation by near-surface snow. Heating of a control volume by absorption of solar radiation depends on the amount of the incident solar radiation, and on the microstructure and composition of the snow. In the model, it does not depend on the thermal diffusivity of the snow nor on the accumulation rate, but in reality both solar absorption and thermal diffusivity depend on snow grain size.

The model is illustrated in Figure 1. The solution for temperature at point $\mathrm{P}$ is fully implicit, meaning it depends upon the most immediate previous values of temperature at point $P$ as well as on the present unknown values at points $U$ and D. Other numerical solutions to Equation (1) are possible, but are often not optimal either in interpretation (e.g. Taylorseries expansions) or in general applicability (e.g. variational formulation) (Patankar, 1980).

\section{Application of the finite-volume model to near-surface snow at the South Pole}

Our goal is to understand the heat and vapour content of the near-surface snow at the South Pole on timescales from minutes to years. The high degree of horizontal homogeneity of East Antarctica and the slow horizontal movement of the ice at the South Pole (approximately $10 \mathrm{~m} \mathrm{a}^{-1}$; Bingham and others, 2007) eliminates the need for horizontal conduction and advection of temperature in the model, allowing us to

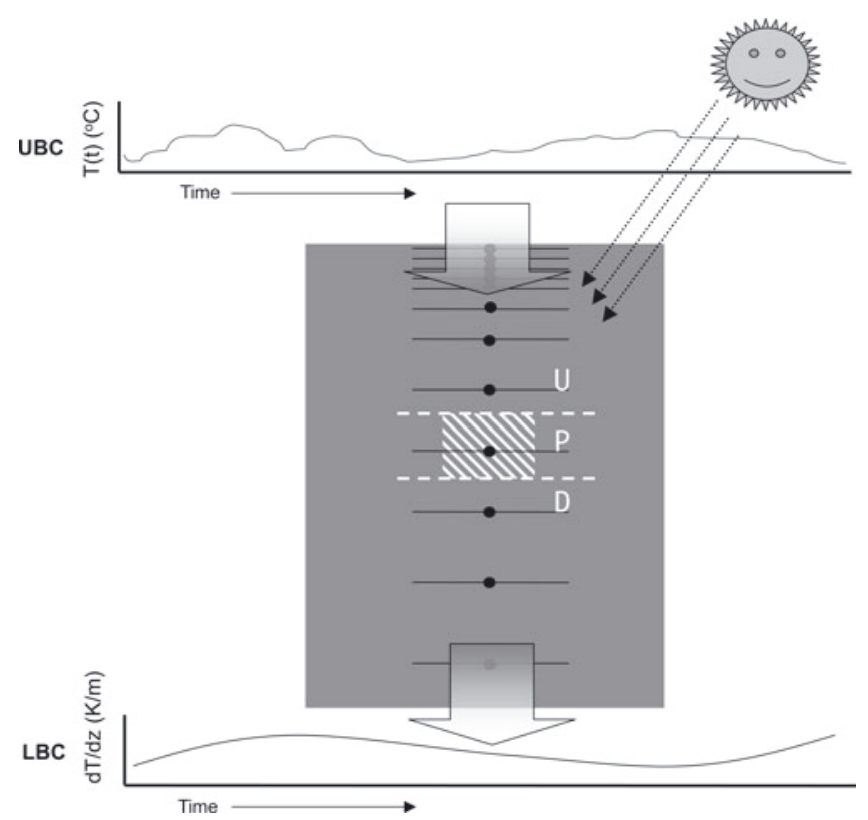

Fig. 1. The box represents the 1-D finite-volume model used to calculate snow temperatures, heating rates and vapour pressures. The thick arrows indicate vertical advection (snow accumulation). The black dots are the points for which implicit solutions are determined at each time-step. The hatched area is one control volume. The sun represents a physical example of a source term for Equation (1), where the solar heating rate is measured in $\mathrm{J} \mathrm{m}^{-3} \mathrm{~s}^{-1}$. The nodes at which we solve for temperature are represented by the solid horizontal lines. The upper boundary condition is skin-surface temperature measured at 9 min intervals, and the lower boundary condition (at $6.5 \mathrm{~m}$ depth) is a measured seasonally varying temperature gradient.

use a simplified 1-D finite-volume model. There is horizontal inhomogeneity in the snow surface in the form of sastrugi, which are wind-carved snow structures of height 5-20 cm at the South Pole. They form primarily in the winter at the South Pole, but become flattened by differential solar heating of their sides during summer (Gow, 1965). Such smallscale horizontal temperature gradients are not represented in this model. Sensitivity tests with the model indicated that the accumulation rate at the South Pole $\left(\sim 80 \mathrm{~mm}\right.$ w.e. $\mathrm{a}^{-1}$; Mosley-Thompson and others, 1999) does not advect temperatures downward into the snow significantly relative to the rate at which temperatures were conducted vertically during the 9 year time period, so advection is not included below. Similar results were found in a modelling study of stable isotopes in firn at Taylor Mouth, Antarctica, above the McMurdo Dry Valleys (Neumann and others, 2005).

We present results primarily from the top metre of the snow because deeper snow retains little memory of synoptic variability. The model depth was set to $6.5 \mathrm{~m}$. This is a compromise between computation time, available seasonal data to constrain the lower boundary, a lower boundary that is far enough away from the near-surface snow so as not to substantially affect the results in the near-surface snow and efficient use of the available upper boundary condition data.

A deeper lower boundary condition is possible, which would allow the use of a constant lower boundary condition rather than the seasonally varying one employed. However, a deeper lower boundary condition model with a constant temperature would substantially shorten the duration of our simulations because it would require many more surface data 

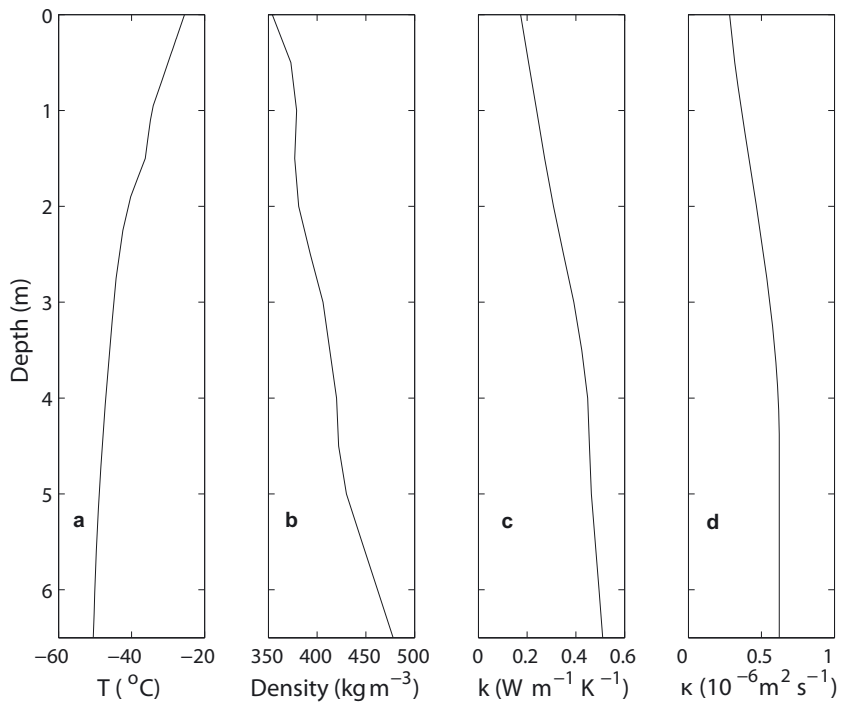

Fig. 2. Near-surface snow properties of the South Pole during the International Geophysical Year (IGY) (Dalrymple and others, 1966) used in the finite-volume model of subsurface temperatures: (a) model initialization temperature profile (31 December 1957); (b) mean annual snow density profile; (c) mean annual thermal conductivity profile; and (d) mean annual thermal diffusivity $\left(\kappa=k / \rho C_{p}\right)$.

for model initialization. A deeper lower boundary condition could also induce a temperature bias in the model because the high interannual variability of mean annual surface temperature (standard deviation of about $1 \mathrm{~K}$ at the South Pole) is still felt at $10 \mathrm{~m}$ depth. Therefore, setting a constant lower boundary condition at $10 \mathrm{~m}$ depth, for example, would require assuming a temperature at that depth that is likely to be biased by $\pm 0.3 \mathrm{~K}$ due to interannual variability of surface temperature.

The model snow properties are taken from Dalrymple and others (1966) (Fig. 2b-d); they vary with depth but are kept constant in time. The heat capacity of the snow is $1710 \mathrm{Jg}^{-1} \mathrm{~K}^{-1}$. It varies insignificantly with depth (Dalrymple and others, 1966), so is not shown. The vertical resolution is $1 \mathrm{~cm}$ in the top $30 \mathrm{~cm}$, then becomes step-wise coarser to $50 \mathrm{~cm}$ at $2 \mathrm{~m}$ depth and uniform at $50 \mathrm{~cm}$ from 2 to $6.5 \mathrm{~m}$, as shown schematically in Figure 1. The model is constrained at its lower boundary by a climatological temperature gradient taken from the temperature-profile annual cycle of Dalrymple and others (1966).

The upper boundary condition is a continuous time series of skin-surface temperature from 1994 to 2003 at 9 min resolution derived from routine measurements of upwelling infrared radiation collected by NOAA ESRL-GMD with a downward-looking broadband pyrgeometer (sensitive to wavelengths of $4-50 \mu \mathrm{m}$ ) with a ventilated dome, deployed $1 \mathrm{~m}$ above the snow surface. The infrared data were converted to skin-surface temperatures using the Stefan-Boltzmann law and a snow emissivity value of 0.98 (Warren, 1982). The longwave emission from snow comes from the top millimetre of snow. Therefore, the skin-surface temperature retrieved from longwave data represents the temperature of the top millimetre. Comparison of skin-surface temperatures retrieved from longwave data to snow-surface temperatures measured by thermistors resting on the snow surface from the 2001 South Pole winter (Hudson and Brandt, 2005) shows a high correlation $\left(r^{2}>0.99\right)$ and mean residual of less than $1 \mathrm{~K}$. The longwave infrared dataset has $3 \mathrm{~min}$ resolution from 1994 to 1997 , and $1 \mathrm{~min}$ resolution from 1998 to 2003. A 9 min running mean was applied to the entire dataset, and missing data were acquired using linear interpolation prior to the conversion to temperature.

The only energy input to the model comes from the upper and lower boundary conditions. Solar heating of snow occurs during summer, but we do not include it explicitly. Most of the absorption is of near-infrared radiation, which occurs in the top few millimetres of snow (fig. 4 of Brandt and Warren, 1993), within the topmost half-volume $(5 \mathrm{~mm})$ of the model. This absorption is of the same order as the effective infrared emission depth of snow $(<1 \mathrm{~mm})$. Therefore, it is largely included by using the skin-surface temperature from the upwelling infrared data. Inclusion of solar heating in the source term is not physically compatible with a skin-surface temperature upper boundary condition. Solar absorption of snow results in a small temperature maximum, as much as $0.2 \mathrm{~K}$, a few millimetres below the snow surface during December (Brandt and Warren, 1993).

If our model were instead constrained at the surface by radiative and turbulent fluxes, then absorption of solar radiation in the snow as a function of depth could be included. We decided against this approach because of the large potential uncertainty associated with estimating sensible heat fluxes on short timescales in extremely stable boundary layers, as mentioned previously.

Heat can also be forced into the snow by wind pumping (Colbeck, 1989). The extent to which this effect is significant depends on the square of the surface wind speeds and the height of the surface topography, both of which are greater on average during the winter. This process will likely serve to increase the effective thermal conductivity and pore-space water-vapour transport within the snow. Windpumping was found to be insignificant to heat transport below approximately $20 \mathrm{~cm}$ at the South Pole (Brandt and Warren, 1997), but may have a significant effect on snow temperatures closer to the surface under appropriate conditions (i.e. low temperature gradients or high wind speeds) (Albert and McGilvary, 1992).

Surface and subsurface melting has been modelled in Antarctic snow, but it has been found to be insignificant above $2500 \mathrm{~m}$ a.s.l. (Liston and Winther, 2005). The elevation of the South Pole is $2835 \mathrm{~m}$ a.s.I. Snowmelt has never been reported at the South Pole; we therefore do not consider its effects here in our model.

\section{Model behaviour, initialization and validation}

The finite-volume model was tested in several ways to assess its behaviour, precision and accuracy. A simulation of a simple scenario is shown in the inset in Figure 3. The snowpack is initially set to be isothermal at $-40^{\circ} \mathrm{C}$, with a constant surface-temperature forcing of $-30^{\circ} \mathrm{C}$ and a uniform thermal diffusivity. Figure 3 shows the error in the numerical results after 2 days by comparison to the analytical solution for this scenario (Carslaw and Jaeger, 1959, p. 62-63). The figure shows that the errors in the numerical finite-volume model drop to the order of $\mathrm{mK}$ for a resolution of $1 \mathrm{~cm}$ and $2 \mathrm{~min}$. These results indicate that the spatial resolution of the model in the top $30 \mathrm{~cm}$ is adequate to determine snow temperatures on short timescales under a steep temperature 
gradient, which often occurs in the top $30 \mathrm{~cm}$ of snow at the South Pole.

We also tested whether the model leaked energy and, if not, how long the model would take to converge on a repeatable annual cycle. Energy leakage is not likely in a finitevolume model of this construction. Initialized in this test as isothermal at $-49.5^{\circ} \mathrm{C}$, the mean annual surface temperature at the South Pole, the model took 1 year to converge. Our definition of convergence here is that the mean absolute value of the temperature profile residual between one day during the last (tenth) year of the simulation and the same day during a prior year is less than $0.5 \mathrm{~K}$. For the simulations presented below, the model was initialized using the 31 December temperature profile from Dalrymple and others (1966) taken during their 1957/58 field season. Using a realistic profile of snow temperature facilitates much faster model spin-up.

The finite-volume model results are sensitive to the shape and magnitude of the seasonally varying temperature gradient used as the model's lower boundary condition (not shown). The seasonally varying temperature gradient at $6.5 \mathrm{~m}$ from Dalrymple and others (1966) is not a simple sinusoid or annually symmetric; it ranges from $0.95 \mathrm{~K} \mathrm{~m}^{-1}$ in November to $-0.5 \mathrm{~K} \mathrm{~m}^{-1}$ in March. It does not integrate to zero. Thus, there is a bias of $0.2 \mathrm{~K} \mathrm{~m}^{-1}$ in the lower boundary condition, which results in a positive absolute bias less than $0.5 \mathrm{~K}$ in the top $1 \mathrm{~m}$ of the model, but the bias is as large as $1.5 \mathrm{~K}$ at a depth of $5 \mathrm{~m}$. Given the larger potential biases in the lowest $2.5 \mathrm{~m}$ of the model, we generally present data only for the top $4 \mathrm{~m}$ of the snow. Rather than adjust the observed lower boundary condition to average to zero annually, which would impose our own expectations on the length and/or magnitude of the cooling and warming seasons at $6.5 \mathrm{~m}$, we accept that the measurements may cause a small bias in our results.

A further positive $1 \mathrm{~K}$ bias may exist in our results due to the use of a low snow emissivity in the skin-surface temperature retrieval from longwave upwelling fluxes (LUF). We used an emissivity of 0.98 (Warren, 1982); however, the effective emissivity may actually be 0.99 or greater, including the reflection of atmospheric longwave emission (Hori and others, 2006). A final bias, as stated earlier, exists due to the exclusion of solar heating of the snow. This bias is small and negative, $-0.2 \mathrm{~K}$ (Brandt and Warren, 1993), in the top few millimetres during summer.

Uncertainties in temperature, heating rate and net heat flux into snow were determined through propagation of errors in the Stefan-Boltzmann law, heat-flux and heating-rate equations. Results are given for two different periods, as the longwave upwelling data were available at 3 min frequency for 1994-97 and at 1 min frequency for 1998-2003. Uncertainties in the upper boundary condition and snow properties used in these calculations are: LUF $= \pm 4 \mathrm{~W} \mathrm{~m}^{-2}$ (personal communication from $\mathrm{E}$. Dutton, 2004); $k= \pm 0.1 \mathrm{~W} \mathrm{~m}^{-1} \mathrm{~K}^{-1}$ (Brandt and Warren, 1993); $C_{\mathrm{p}}= \pm 6 \mathrm{~J} \mathrm{~kg}^{-1}$ (Dalrymple and others, 1966); and $\rho= \pm 35 \mathrm{~kg} \mathrm{~m}^{-3}$ (personal communication from H. Conway, 2007). For the period 199497 , the $1 \sigma$ errors in temperature, heating rate and net heat flux are $\pm 0.8 \mathrm{~K}, \pm 6.4 \mathrm{~K} \mathrm{~d}^{-1}$ and $\pm 3.8 \mathrm{~W} \mathrm{~m}^{-2}$, respectively. For the period 1998-2003 the $1 \sigma$ errors in temperature, heating rate and net heat flux are $\pm 0.4 \mathrm{~K}, \pm 3.6 \mathrm{Kd}^{-1}$ and $\pm 2.6 \mathrm{~W} \mathrm{~m}^{-2}$, respectively. The values are for $9 \mathrm{~min}$ averages; random errors decrease substantially when averaged over hours or days.

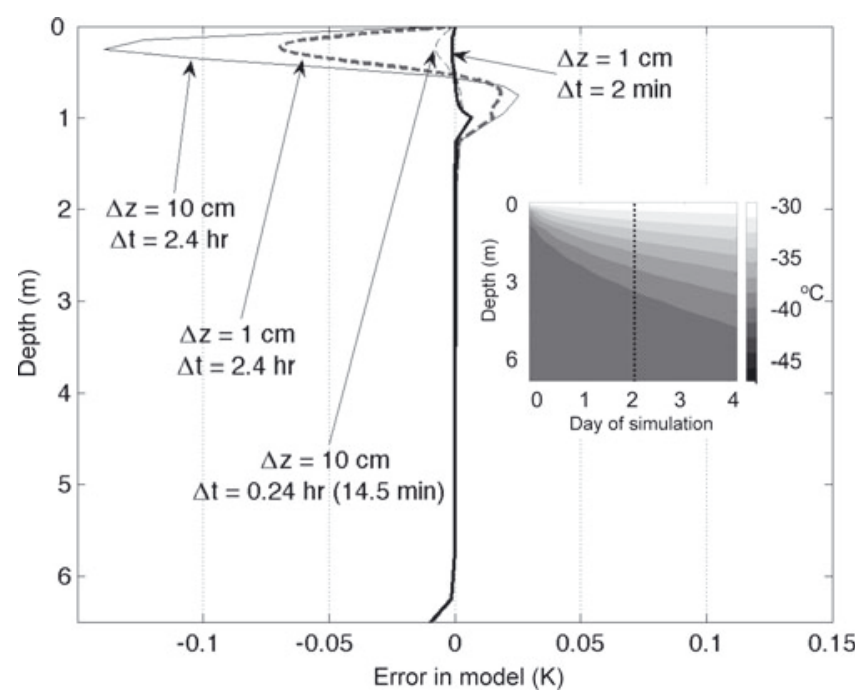

Fig. 3. Accuracy of the numerical solution with respect to the anaIytic solution as a function of depth and time resolution (K). The error is shown for day 2 of the simulation, shown in the inset. The conditions for this scenario were a constant upper boundary condition of $-30^{\circ} \mathrm{C}$ and an initial isothermal temperature profile of $-40^{\circ} \mathrm{C}$.

\section{SNOW TEMPERATURES, HEATING RATES AND VAPOUR PRESSURES}

The heat fluxes and vapour pressures in the near-surface snow at a given point in time and space are the result of its integrated response to the instantaneous radiative and turbulent forcings at the surface and to the heat stored in the snow from previous months and years. Based on monthly mean energy balance at the snow surface for this time period (Town, 2007), it appears that radiation and sensible heat fluxes are the most important forcings for the skin-surface temperature. They are on the order of $10-20 \mathrm{~W} \mathrm{~m}^{-2}$ throughout the year, and of opposite sign. Frost deposition and sublimation are second-order contributors due to the low temperatures, a net deposition of 2-3 mm over the annual cycle. However, these results are subject to the uncertainties in parameterizations of the stable boundary layer mentioned earlier.

In this section we first give a brief summary of relevant features of the climate of the South Pole, to place the significance of the finite-volume model results in perspective relative to the atmospheric surface forcing. We then present our results for subsurface temperatures, net heat fluxes, heating rates and pore-space vapour pressures. We have simulated 10 years (1994-2003) of snow temperatures, heating rates and vapour pressures, although we present only the last 9 years (1995-2003) owing to the 1 year of model equilibration.

\section{The climate of the South Pole}

The climate of the South Pole has been studied extensively since the International Geophysical Year (IGY, 1957/58). Aspects of the climate and weather of the South Pole relevant to this work are presented or reviewed by Dalrymple and others (1966), Schwerdtfeger (1970, 1984), Carroll (1982), King and Connolley (1997), Neff (1999), Hudson and Brandt (2005) and Town and others $(2005,2007)$. It has been shown that the South Pole, and most of the East Antarctic plateau, has an annual temperature cycle with a coreless winter (Fig. 4), i.e. a winter with no well-defined minimum in 


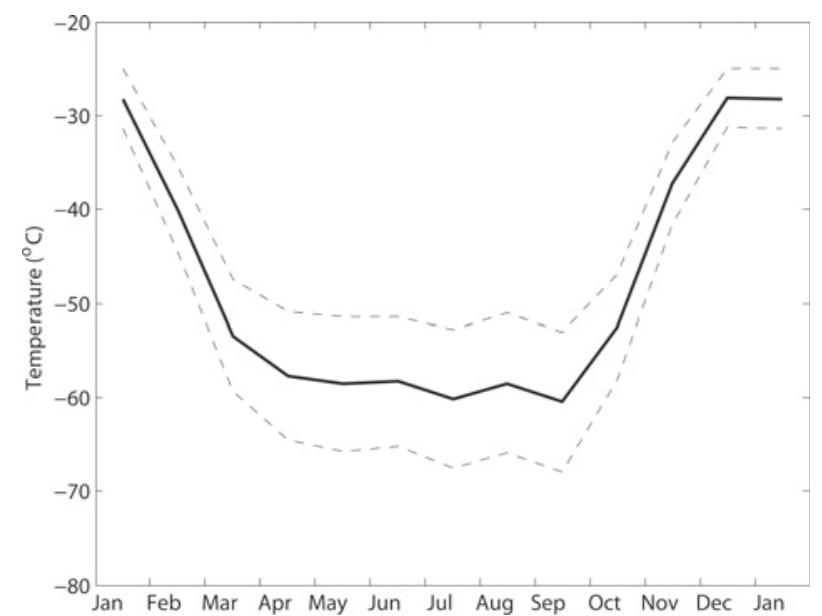

Fig. 4. Monthly mean $2 \mathrm{~m}$ atmospheric temperature for the South Pole for 1994-2003. The dashed curves show the standard deviation of daily average temperatures about the monthly mean.

temperature (Warren, 1996). Figure 4 shows that the dayto-day variability in $2 \mathrm{~m}$ atmospheric temperature is much greater during winter than during summer. The surface winds (not shown) are stronger on average during winter (approximately $6 \mathrm{~m} \mathrm{~s}^{-1}$ ) than summer (approximately $4 \mathrm{~m} \mathrm{~s}^{-1}$ ). However, daily variability in wind speed varies little throughout the year.

The association between $2 \mathrm{~m}$ temperature, wind speed, cloud cover and regional weather patterns at the South Pole was examined by Neff (1999) and Town and others (2007). In general, cloud cover is associated with higher temperatures and higher wind speeds throughout the year. This association is due to alternating influences of relatively strong cyclonic weather systems originating from the coast and calm geostrophic flow circulating along elevation contours of the East Antarctic plateau. In general, the cyclonic activity advects heat, moisture and cloud cover to the South Pole from the Weddell and Bellingshausen Seas. The anticyclonic, geostrophic flow aloft is set up by radiative cooling of the surface to space. This cooling generates a downslope pressure gradient that is balanced by the Coriolis force. Near the surface, the geostrophic force balance is perturbed by friction, directing some of the flow downslope. This is known as an inversion wind (Schwerdtfeger, 1984), which is the source of katabatic winds at the coast of Antarctica.

The correlation of higher temperatures with cloud cover is stronger during winter than during summer. Episodic fluctuations in $2 \mathrm{~m}$ atmospheric temperatures of up to $30 \mathrm{~K}$ are possible during winter, whereas synoptically similar episodes result in much smaller temperature fluctuations during summer. This is due primarily to three factors. The Southern Hemisphere winter is typically stormier than the Southern Hemisphere summer (Simmonds and others, 2003). Over the Antarctic plateau this means that there is more cyclonic activity to advect heat and moisture towards the South Pole during winter. In addition, the temperature gradient from the Southern Ocean to the continental interior is steeper during winter. Therefore, cyclones that do reach the South Pole will be warmer relative to ambient conditions than their summertime counterparts. Finally, the lack of solar heating during winter allows strong surface-based atmospheric temperature inversions under clear skies. The temperature inversions are

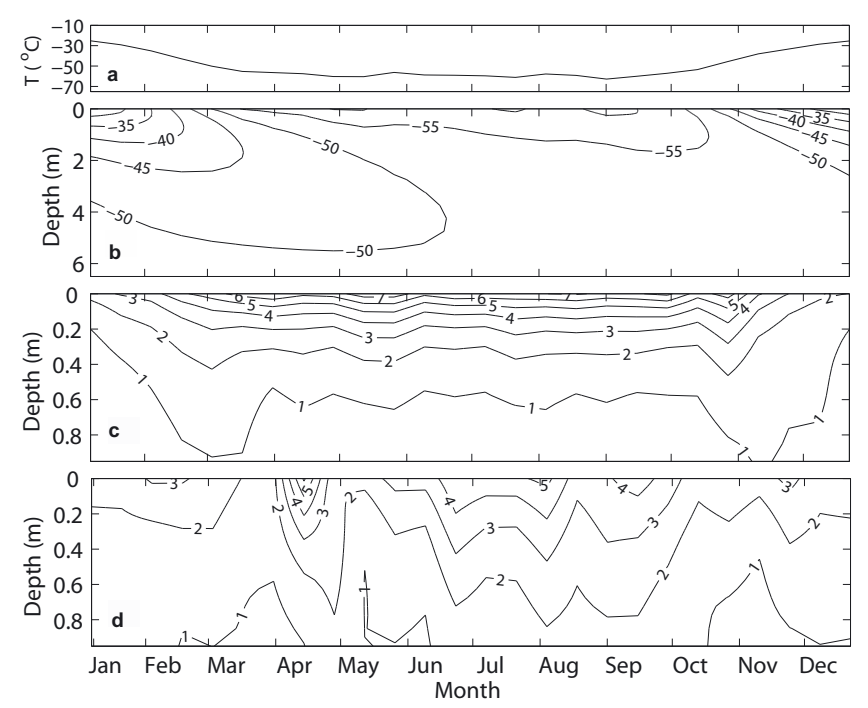

Fig. 5. Mean seasonal temperatures, short-term variability and interannual variability for 1995-2003: (a) climatological skinsurface temperature from longwave upwelling radiation measurements, the upper boundary condition for the 9 years of simulation $\left({ }^{\circ} \mathrm{C}\right)$; (b) 9 year averages of mean 2 week subsurface temperatures $\left({ }^{\circ} \mathrm{C}\right)$; (c) 9 year averages of mean 2 week standard deviation of 9 min temperatures (K); and (d) 9 year standard deviation (K) of means in (b).

very sensitive to changes in wind speed and cloud cover. Therefore, $2 \mathrm{~m}$ atmospheric temperatures fluctuate more on short timescales during winter than summer in response to similar changes in synoptic conditions.

\section{Subsurface temperatures}

The seasonal cycle of near-surface snow temperatures has been reported or utilized by many researchers around Antarctica: in Dronning Maud Land (e.g. Bintanja, 2000; Reijmer and Oerlemans, 2002; Liston and Winther, 2005; Van As and others, 2005; Van den Broeke and others, 2005, 2006), in West Antarctica (e.g. Morris and Vaughan, 1994), at the Antarctic coast (e.g. King and others, 1996), the South Pole (Dalrymple and others, 1966; Carroll, 1982; Jackson, 1982; Brandt and Warren, 1993, 1997; McConnell and others, 1998) and multiple other locations (e.g. King and Connolley, 1997; Bailey and Lynch, 2000). The short-term variability of near-surface snow temperatures has been illustrated by a subset of those above (King and others, 1996; McConnell and others, 1998; Bintanja, 2000; Reijmer and Oerlemans, 2002; Van As and others, 2005; Van den Broeke and others, 2005, 2006). However, beyond summertime investigations of the diurnal cycle, the short-term variability and the interannual variability of near-surface snow temperatures has yet to be quantified.

We first present the mean annual cycle of skin-surface temperature and the mean annual cycle of snow temperatures (Fig. 5a and b). These results compare well with the in situ data from 1958 (Dalrymple and others, 1966) and the winter of 1992 (Brandt and Warren, 1997) within the interannual variability shown in Figure $5 \mathrm{~d}$.

The mean short-term variability is shown in Figure 5c. Most of the temperature variability on short timescales is contained in the topmost metre. In general, the snow shows greatest variability during winter. The 2 week variability at $1 \mathrm{~m}$ depth is greatest during February-April and November-December. 

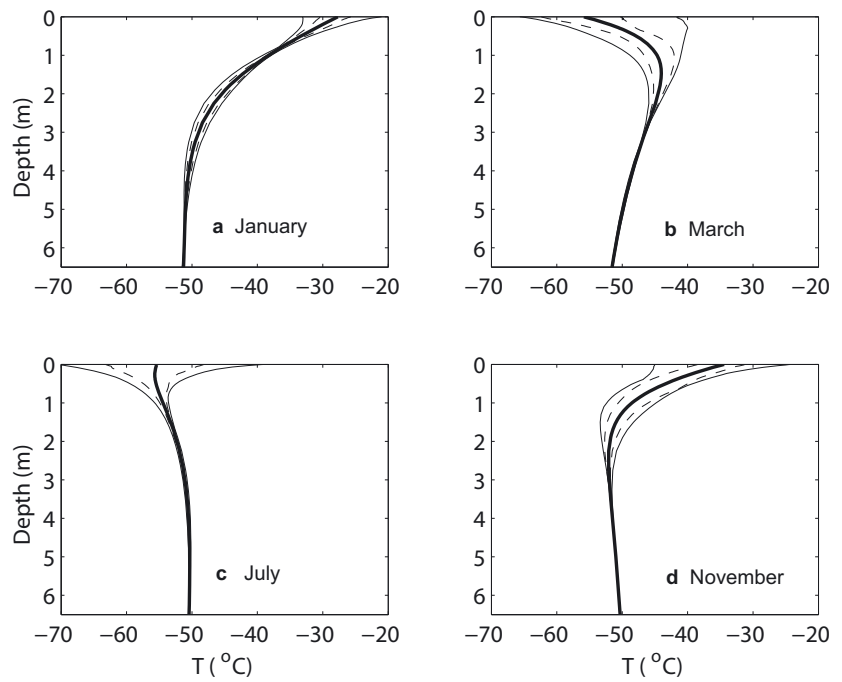

Fig. 6. Thick curves show monthly snow-temperature profiles $\left({ }^{\circ} \mathrm{C}\right)$ from the finite-volume model for January (a), March (b), July (c) and November (d) of 1996 . The 5\%, 25\%, 75\% and 95\% distribution values are also indicated as thin solid and dashed curves (from left to right).

During these times, the snowpack is cooling or warming in response to the large seasonal change in atmospheric temperature as well as responding to synoptic variability. Interannually, greater variability is found during winter than during summer (Fig. 5d).

Figures 6 and 7 further illustrate the dynamics of subsurface temperatures on short timescales. The largest variability in temperature is at the surface, as indicated by the $5 \%$ and $95 \%$ extremes shown in Figure 6 . The variability in temperature in the top $50 \mathrm{~cm}$ during January and July is due primarily to synoptic weather influences (i.e. changes in radiative and turbulent fluxes) at the South Pole, with changes in solar elevation playing a minor role during January. The spread in temperatures is larger in July than in January due to the sensitivity of the surface-based atmospheric temperature inversion to changes in the surface energy balance. During July, there is little variability below $1 \mathrm{~m}$ because there is no strong, consistent temperature gradient between the surface and the bottom boundary of the model to force significant changes in temperature. January shows some variability in temperatures between 2 and $4 \mathrm{~m}$ depth as the warm pulse from November and December diffuses into the snow. During March and November, however, the near-surface snow shows a broad distribution of temperatures due both to synoptic weather influences and changes in solar elevation.

Sub-daily variability in the top metre of snow is shown for these four months of 1996 in Figure 7. The panel above each contour plot shows the skin-surface temperature. The influence of synoptic variability on the temperature profiles is evident from these panels. The snow shows significant variability in the top $30 \mathrm{~cm}$ during summer (January) due to fluctuations of the skin-surface temperature on hourly, or longer, timescales. Below $30 \mathrm{~cm}$, temperature variations with time and depth are less dramatic. Larger variability in skin-surface temperatures during winter leads to increased temperature variations in the topmost snow. These large temperature fluctuations penetrate deeper during winter due to the stronger surface forcing. The dual influences of dramatically changing
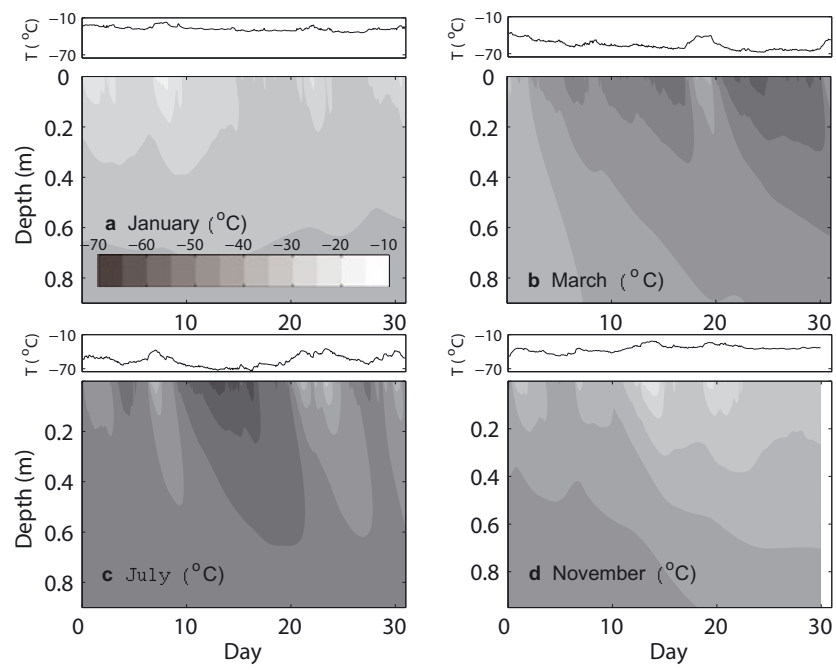

Fig. 7. Snow temperatures for the months of January (a), March (b), July (c) and November (d) of $1996\left({ }^{\circ} \mathrm{C}\right)$. The time series in the panel above each contour plot is the skin-surface temperature used as forcing for that month.

solar irradiance and synoptic variability are evident in Figure 7 for March and November. The seasonal warming or cooling of the snow during these transitional months, illustrated as wide distribution boundaries in Figure 6, is shown as steadily sloping temperature contours in Figure $7 \mathrm{~b}$ and $\mathrm{d}$.

Figure 7 shows clearly that temperature gradients in the near-surface snow can change direction several times a month in response to variable synoptic conditions. This will be important in estimating short-term net heat fluxes into the snow, and may have significant implications in studies of snow metamorphism.

\section{Net heat fluxes and heating rates}

Using specified profiles of thermal conductivity, heat capacity and temperature, we computed snow heat fluxes and heating rates from the computed snow temperatures. The snow heat fluxes were calculated as linear gradients in snow

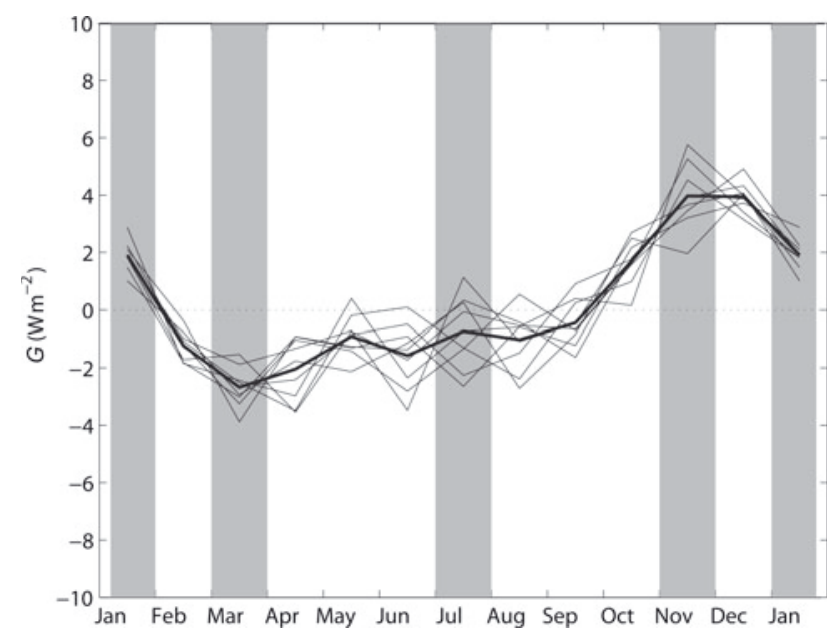

Fig. 8. Monthly mean net heat fluxes into the snow $(G)$ for 19952003 are shown by the thin black curves $\left(\mathrm{W} \mathrm{m}^{-2}\right)$. The 9 year mean of monthly mean $G$ is shown by the thick black curve. The casestudy months used in this paper are shaded. Positive $G$ is directed downward into the snow. The month of January is repeated. 

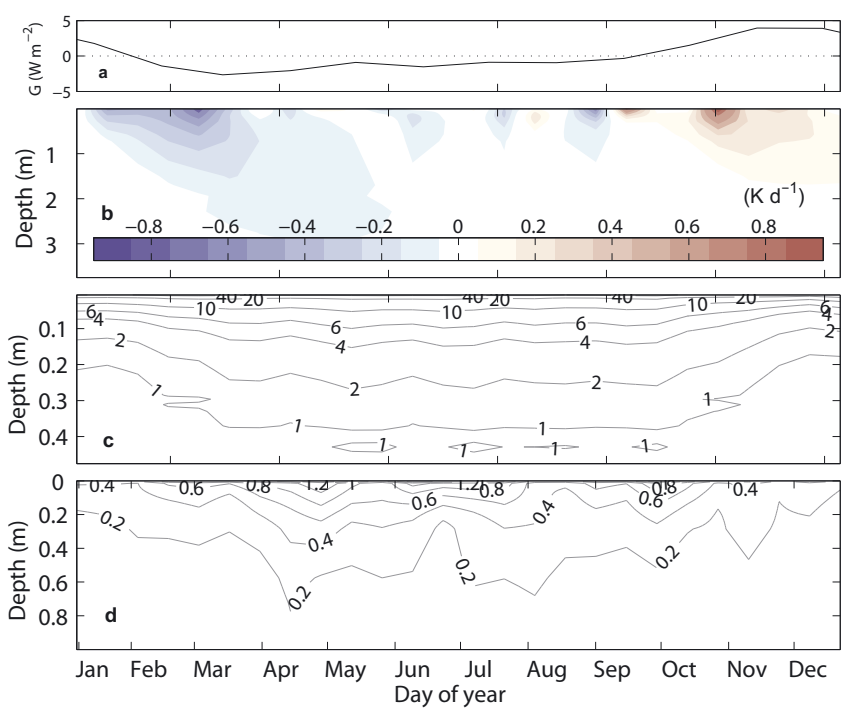

Fig. 9. Snow heating-rate climatology for 1995-2003: (a) net heat flux into snow $(G)$, as shown in Figure $8\left(\mathrm{~W} \mathrm{~m}^{-2}\right)$; (b) 2 week mean heating rates $\left(\mathrm{Kd}^{-1}\right)$; (c) 2 week standard deviation of heating rates $\left(\mathrm{K}^{-1}\right)$; and (d) $1 \sigma$ interannual variability about the mean shown in (b) $\left(\mathrm{Kd}^{-1}\right)$. Note the different scales on the vertical axes of (b), (c) and (d).

temperature multiplied by the thermal conductivity of the snow at that depth. Heating rates were computed as the divergence of the snow heat fluxes into a volume. The net heat fluxes into the snow $(G)$ are shown in Figure 8. They were computed from the topmost two temperatures in the finitevolume model and the thermal conductivity of the snow at that level. A positive $G$ indicates a downward-directed heat flux into the snow (i.e. heating the snow).

The monthly mean net heat fluxes into the snow shown here compare well with other fluxes modelled or observed at the South Pole (Dalrymple and others, 1966; Carroll, 1982; King and Connolley, 1997) and are similar in magnitude and timing to other sites around the continent, despite large differences in latitude, longitude, altitude and continentality (King and Connolley, 1997; Bintanja, 2000; Reijmer and Oerlemans, 2002; Van den Broeke and others, 2005, 2006).

The seasonal cycle of net heat flux into snow has an unusual shape; it is not sinusoidal or symmetric in amplitude. The rate of energy exchange between snow and atmosphere is greatest during the months when the temperature difference between snow and atmosphere is greatest. The heat content of the snow is greatest during January, but the largest downward temperature gradient (upward flux of energy) occurs in March as the sun sets. In the multi-year mean, cooling continues throughout the winter. Heating of the snow during November and December is more dramatic and shorter-lived because the sun must rise to elevations large enough to significantly heat the snow and overlying atmosphere. The net heat flux into snow integrates to $0.07 \mathrm{~W} \mathrm{~m}^{-2}$, which is zero within the standard error of the 9 year mean. The snowpack is therefore not changing temperature in the annual mean over this time period.

The monthly mean winter net heat flux into snow is negative (upward), and progresses steadily to zero from April to September in the 9 year mean (thick line in Fig. 8). However, it is clear that this steady increase is a result of multiyear averaging. The net heat flux into snow is consistently
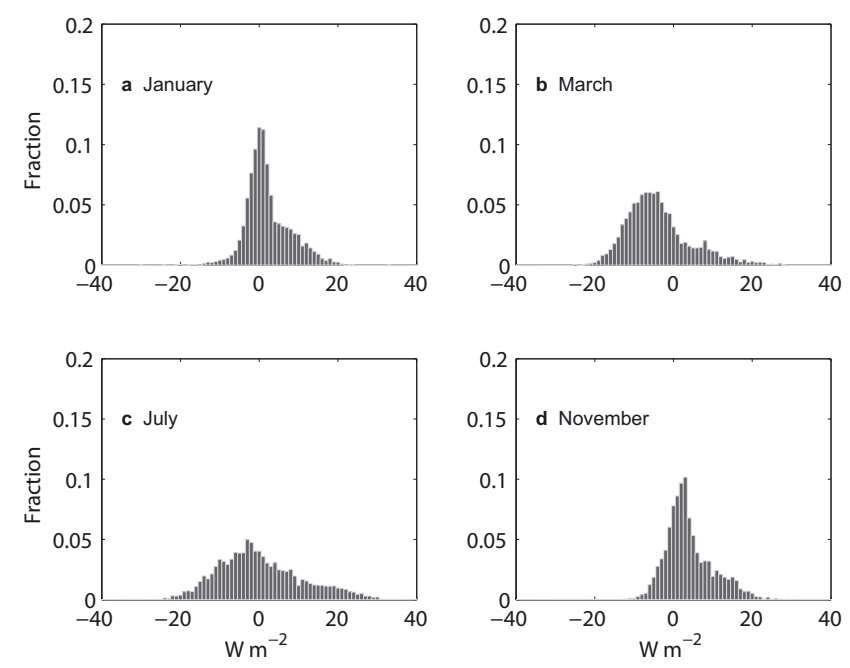

Fig. 10. Histograms of net heat flux into snow $(G)$ for four months of $1996\left(\mathrm{Wm}^{-2}\right)$. The data have 9 min time resolution and the bin width is $1 \mathrm{Wm}^{-2}$. These distributions are representative of 1995-2003. The means and $1 \sigma$ standard deviations are (a) $2.1 \pm 5.6 \mathrm{~W} \mathrm{~m}^{-2}$ for January; (b) $-3.9 \pm 8.1 \mathrm{~W} \mathrm{~m}^{-2}$ for March; (c) $0.3 \pm 10.7 \mathrm{~W} \mathrm{~m}^{-2}$ for July; and (d) $4.0 \pm 6.1 \mathrm{~W} \mathrm{~m}^{-2}$ for November.

directed upward from February to April. After April, the nearsurface snow has lost most of the memory of the previous summer, so the influence of heat advected in from the coast can dominate the monthly mean net heat flux into snow. In general, energy is still being drawn from the snow surface by turbulent fluxes and radiation loss to space throughout the winter. Any given month between May and September will therefore likely have a negative net heat flux into snow, but its magnitude depends more on the recent history of energy advection to the Antarctic plateau from the coast than on the remaining summer heat content of the snow.

In the monthly mean, turbulent and radiative energy transfer are larger components of the surface energy balance than the net heat flux into snow shown here, often an order of magnitude larger (Town, 2007). The seasonal heat stored in the snow from the summer and released to the atmosphere during autumn is limited by the diffusivity of the snow. There is a significant amount of energy storage and energy reflux on shorter timescales, which consistently averages out on monthly timescales. The effect of the net heat flux into snow is shown as snow heating rates in Figure 9.

Prior work on short-term variability of net heat flux into snow in Antarctica is limited primarily to summertime investigations of diurnal variations in the surface energy balance. In Dronning Maud Land, the diurnal cycle can range from $\pm 10 \mathrm{~W} \mathrm{~m}^{-2}$ to $\pm 20 \mathrm{~W} \mathrm{~m}^{-2}$, proceeding inland from the coast (Bintanja, 2000; Reijmer and Oerlemans, 2002; Van den Broeke and others, 2006). The diurnal range is largest under clear skies. It is attenuated under overcast skies, due to the cloud's absorption of downwelling shortwave radiation and emission of longwave radiation (Van den Broeke and others, 2006). Variability in mean daily net heat flux into snow during summer is on the order of $\pm 8 \mathrm{~W} \mathrm{~m}^{-2}$ on the high plateau in Dronning Maud Land (Van As and others, 2005).

The South Pole has no 24 hour cycle of solar elevation, so all the sub-daily variability in the net heat flux into snow 

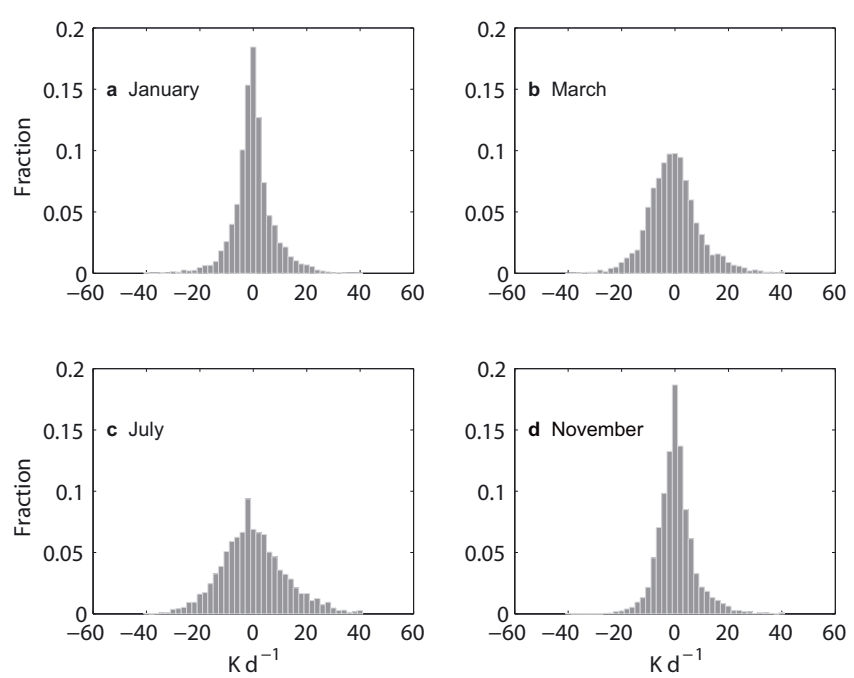

Fig. 11. Histograms of $9 \mathrm{~min}$ heating rates averaged over the top $10 \mathrm{~cm}$ of snow for four months of $1996\left(\mathrm{Kd}^{-1}\right)$. The data have $9 \mathrm{~min}$ time resolution, and bin widths are $2 \mathrm{Kd}^{-1}$. These distributions are representative of 1995-2003.

comes from variations in synoptic conditions such as cloud cover, wind speed and temperature. The effect of synoptic variability can clearly be large, sometimes as large as the diurnal solar variation at those sites. Mean variability $(1 \sigma)$ in 9 min net heat flux into snow ranges from a minimum in December of $\pm 5 \mathrm{~W} \mathrm{~m}^{-2}$ to a mean winter (April-September) variability of $\pm 10 \mathrm{~W} \mathrm{~m}^{-2}$. Histograms of 9 min net heat flux into snow for January, March, July and November of 1996 are shown in Figure 10. Figure 11 shows histograms of the resulting heating rates in the topmost $10 \mathrm{~cm}$ of snow.

The histograms in Figures 10 and 11 are asymmetric. The distribution is always skewed to larger net heat fluxes and heating rates, regardless of season, a phenomenon also noticed in the distribution of winter surface temperatures at Plateau Station (Kuhn and others, 1975). This is largely a result of synoptic activity, which at the 'pole of cold' can only heat the snow surface. The limit on the rate of downward heat flux is related to the rate that heat can be advected in from the coast. The upward (negative) heat fluxes are limited by the thermal conductivity of the snow, and the rate of radiative cooling at the surface. The radiative cooling rate drops quickly with decreasing temperature; it is proportional to the fourth power of temperature. Winter months show a wider spread than summer months due to the surface-based atmospheric temperature inversion.

Sub-daily $(9 \mathrm{~min}$ ) heating rates can vary by as much as $40 \mathrm{Kd}^{-1}(1 \sigma)$ at the snow surface (Figs 9c and 11). The submonthly variability in heating rates extends deeper in winter than in summer because the atmospheric forcings are larger and more variable during winter. The interannual variability of heating rates is largest close to the surface, and also larger during winter than summer (Fig. 9d). Below a depth of approximately $60 \mathrm{~cm}$, the interannual variations have diffused into a mean, climatological heating rate.

The heating rates in Figure 11 are more symmetric about their means than the corresponding net heat flux into snow. The shape of the distribution changes with season as the atmospheric and radiative influences at the surface change. The narrow distributions for January and November in Figure 11 result from weaker synoptic activity and solar forcing
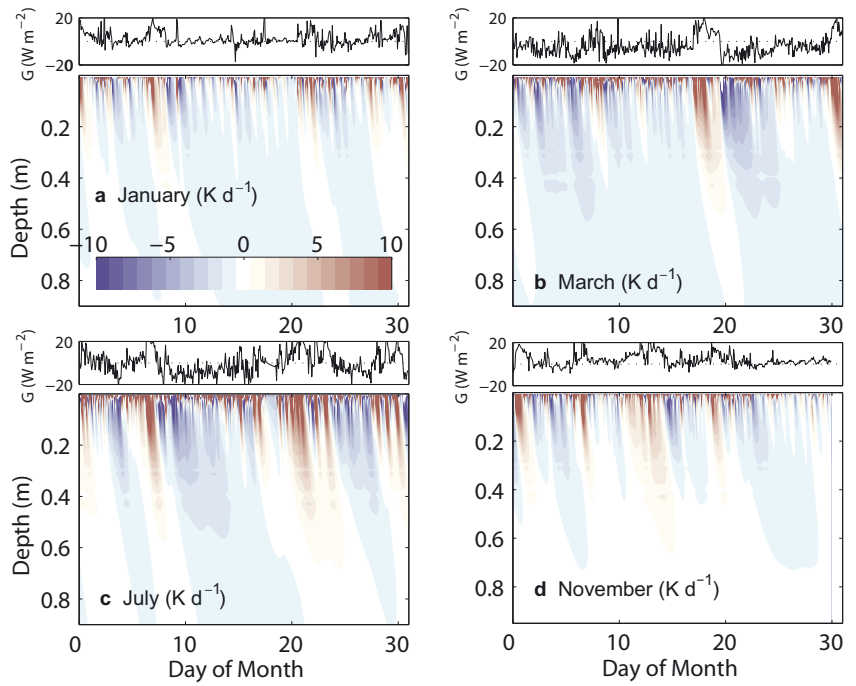

Fig. 12. Snow heating rates for months of $1996\left(\mathrm{Kd}^{-1}\right)$. The time series in the panel above each contour plot is net heat flux into snow $(G)$ for that month $\left(\mathrm{W} \mathrm{m}^{-2}\right)$.

of snow-surface temperatures during spring and summer. In terms of the variability of temperatures and heating rates, 1996 is representative of the 9 years modelled here. Despite variability within each month, the net heat flux into snow consistently averages out to very similar monthly mean values each year. This is unexpected because it requires the net synoptic influence on the surface to be approximately the same from year to year in a given month.

In Figure 12, we examine the same months from 1996 that were shown in Figure 7 . Heating rates can be as large as $10 \mathrm{Kd}^{-1}$ or greater in the bulk of the near-surface snow, but such heating rates are often followed immediately by significant cooling. The narrow panel above each contour plot shows net heat flux into snow. Whereas the monthly mean net heat flux into snow never exceeded $\pm 6 \mathrm{~W} \mathrm{~m}^{-2}$ in the 9 years simulated here, the 9 min values of net heat flux can be as large as $\pm 20 \mathrm{~W} \mathrm{~m}^{-2}$. The amount of energy refluxed each month between the snow and the atmosphere is greater during the winter than during the summer. Even though the net heat flux into snow on short timescales is large, the peaks are smaller than the largest mean daily excursions observed by Carroll (1982). However, our results generally confirm the short-term behaviour of the net heat flux into snow estimated by Carroll (1982).

Interannual variability of heating rates (Fig. 9d) is of the same order as that of the climatological heating rates in the topmost few centimetres during March and November. The heating rates are much more variable interannually and at greater depth during winter without the dominating influence of the sun.

\section{Subsurface vapour pressures}

Understanding the seasonal cycle and variability of subsurface vapour pressures is important for a number of applications: snow metamorphism, snow microstructure and analysis of paleoclimate records. Here we present vapour pressures in the near-surface snow at the South Pole calculated from the subsurface temperatures by assuming saturation with respect to ice in the snow pore spaces (Goff and Gratch formula from List, 1949). 


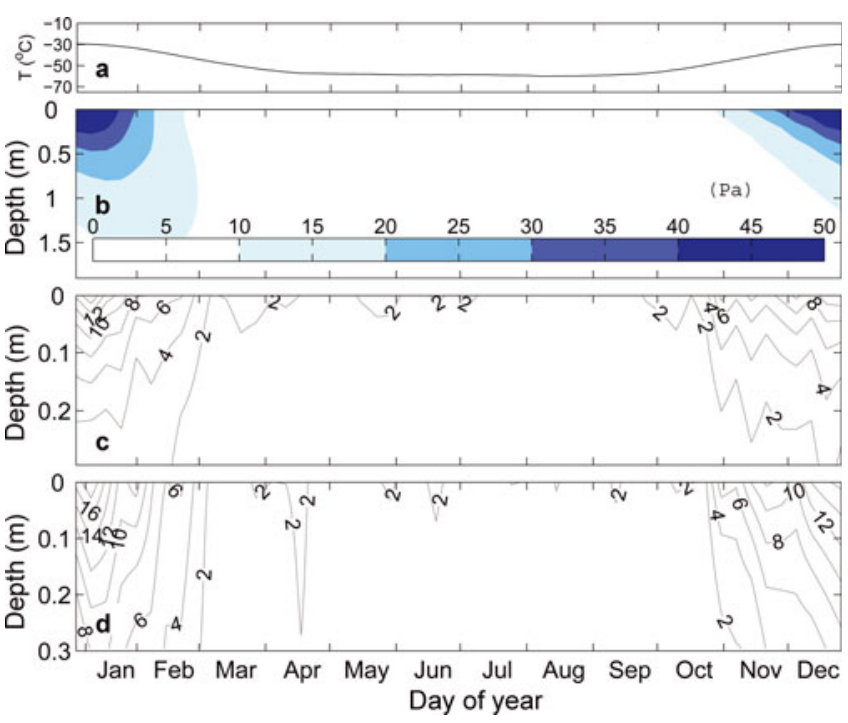

Fig. 13. Climatology of pore-space vapour pressure for 1995-2003: (a) climatological skin-surface temperature from longwave upwelling measurements $\left({ }^{\circ} \mathrm{C}\right)$; (b) 9 year average of 2 week mean vapour pressures (Pa) in the top $2 \mathrm{~m}$; (c) 9 year average of 2 week standard deviation of vapour pressures (Pa) in the top $30 \mathrm{~cm}$; and (d) $1 \sigma$ interannual variability $(\mathrm{Pa})$ in the top $30 \mathrm{~cm}$ about the mean shown in (b).

Figure 13 shows statistics of pore-space vapour pressure for the near-surface snow. The maximum climatological vapour pressure is 60-70 Pa, which occurs at the surface during December and January. The amplitude of the seasonal cycle of vapour pressure drops off much more steeply than the subsurface temperatures in Figure 5 due to the non-linearity of the Clausius-Clapeyron relationship.

It can be seen from Figure 13c that synoptically driven changes in vapour pressures and vapour-pressure gradients occur primarily in the top $10 \mathrm{~cm}$ of the snow. The relatively higher temperatures of summer and the changing vapourpressure gradients during summer can cause significant snow metamorphism, consistent with the idea that most snow metamorphism occurs during summer.

Water vapour can be transported primarily by three mechanisms in cold snow: diffusion across temperature and snowgrain radius gradients; forced ventilation by surface winds (Colbeck, 1989); and convection within the snow. Brandt and Warren (1997) found that forced ventilation (i.e. windpumping) is not significant at the South Pole below the top $20 \mathrm{~cm}$ of the snow. It may turn out to be significant at shallower depths. Even if significant ventilation is found at the South Pole, the snow may still be saturated with water vapour. However, forced ventilation does have implications for paleoclimate records in that the isotopic composition of water vapour in the pore spaces in the top $10 \mathrm{~cm}$ is likely a mixture of the atmospheric $\delta^{18} \mathrm{O}$ and the $\delta^{18} \mathrm{O}$ of the surrounding snow. The isotopic signature of the snow may therefore change after deposition due to ventilation and subsequent vapour transport within the snow (Neumann and others, 2005; Town, 2007), which is likely greater than changes in isotopic content due only to pore-space diffusion down isotopic gradients (e.g. Johnsen and others, 2000; Helsen and others, 2005, 2006).

Figure $13 \mathrm{~d}$ shows significant interannual variability in subsurface vapour pressure due to interannual variability in
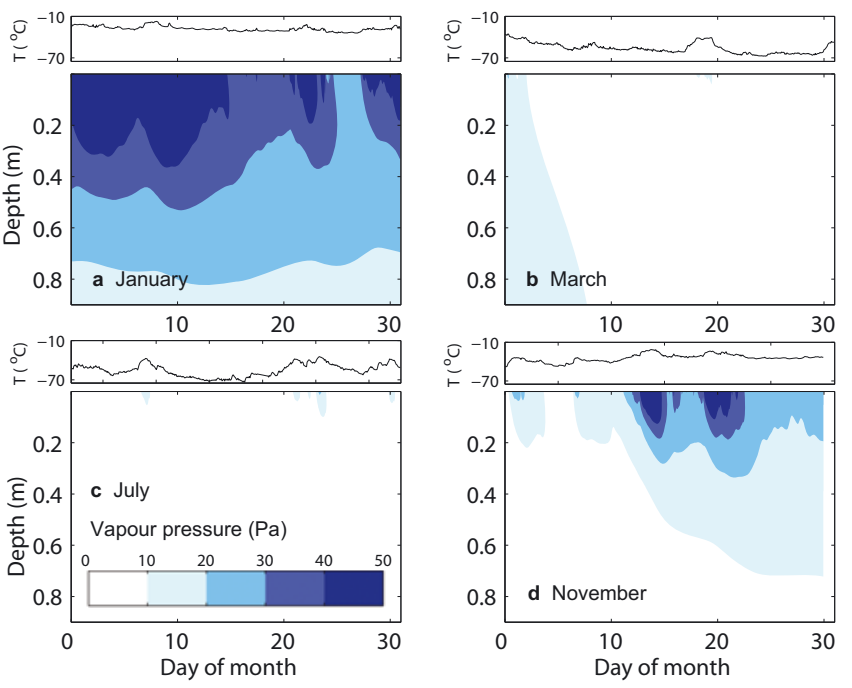

Fig. 14. Pore-space vapour pressures for: (a) January; (b) March; (c) July; and (d) November during 1996. The time series in the panel above each contour plot is the time series of skin-surface temperature for that month.

synoptic forcing of snow temperatures. Figure 14 shows that synoptic variability affects vapour pressure in snow pore spaces. Vapour pressures on short timescales are extremely sensitive to synoptic activity at the surface during summer due to the relatively high temperatures. January 1996 experienced a change in vapour pressure at the surface of more than $30 \mathrm{~Pa}$ due primarily to variability in synoptic activity. The drop in temperature from January to March produces the low mean vapour pressures for March. Despite the large temperature swings during late autumn, winter and early spring, there is not much vapour activity in the snow in March or July because of the low temperatures. The latter half of November begins to show some significant vapour pressure, greater than $1 \%$ of the surface pressure (approximately 600-700 mbar), as the skin-surface temperatures rise with increasing solar elevation. The snow shows relatively high vapour pressures down to approximately $150 \mathrm{~cm}$ from December to February. Again, the variability in the monthly means is confined to the upper 10 or $20 \mathrm{~cm}$ of the snow during summer and adjacent months. Vapour pressures in the snow during the rest of the year are depressed by the low temperatures.

\section{DISCUSSION AND CONCLUSIONS}

Using a 1-D finite-volume model of the snow at the South Pole, we have simulated 9 years of near-surface snow temperatures based on skin-surface temperatures derived from routine measurements of upwelling longwave radiation. Whereas previous reports of similar data are often limited in temporal length or averaged for a month or more, we report results on multi-year means of short- and long-timescale variability to understand the impact of surface temperatures on near-surface snow temperatures, heating rates and vapour pressures.

The behaviour of our model is consistent with the known behaviour of snow temperatures. The temperatures have a mean seasonal cycle that decreases in amplitude with depth. The phase of the seasonal cycle lags the surface temperature forcing deeper in the snow due to the thermal inertia and diffusivity of the snow. The signature of synoptic forcing 
on snow temperatures and heating rates is lost below $60 \mathrm{~cm}$ during summer and below $100 \mathrm{~cm}$ during winter. There is much more variability in snow temperatures and energy reflux to the atmosphere during winter than during summer. This is due to increased synoptic activity during winter and the presence of surface-based atmospheric temperature inversions during winter.

Calculated monthly mean net heat flux into snow matches other measurements and simulations for the South Pole. However, we find net heat fluxes into snow exceeding $20 \mathrm{~W} \mathrm{~m}^{-2}$ on hourly timescales. This has significant implications for understanding the skin-surface and near-surface atmospheric temperatures on short timescales. Although the net heat flux into snow averages out to small values in the monthly mean, the snow can act as a substantial short-term reservoir of energy. This has been observed at other sites in Antarctica, but is quantified systematically over longer time periods for application to other polar studies.

Accurate simulation of short-term energy storage and reflux in the snow may aid mesoscale climate and operational forecasts of near-surface atmospheric conditions in polar regions. The surface energy balance remains a challenge to polar models (King and Connolley, 1997; Hines and others, 1999, 2004; Bailey and Lynch, 2000), which may be due to weaknesses in each component of the energy balance and their feedbacks on one another. Attention should be paid to accurate parameterizations of the seasonal snow properties, locally and regionally, as these fundamentally control heat transfer in snow. Appropriate vertical resolution relative to the temporal resolution of the simulation also requires attention.

It has been suggested (Carroll, 1982) that such a short-term reservoir of energy might be an explanation for the coreless winter. While we believe that the energy reflux from the snow to the atmosphere does play a role in damping near-surface atmospheric temperature variations, this behaviour does not explain the persistent, if episodic, flux of atmospheric energy from the coast to the interior, which is of the order $100 \mathrm{~W} \mathrm{~m}^{-2}$ in the annual mean (Trenberth and Solomon, 1994). The month-to-month constancy of this heat import far exceeds the net heat flux into snow, so it must be the energy source maintaining the coreless winter.

Pore-space vapour pressures in the top $10 \mathrm{~cm}$ range from $60 \mathrm{~Pa}$ in summer to $2 \mathrm{~Pa}$ in winter. The seasonal cycle is damped with depth. Thus, post-depositional processes such as stable-isotope modification happen predominantly during the short summer and in the top 40-60 cm of the snow (Town, 2007). At the South Pole, the snow accumulation rate is 20 $25 \mathrm{~cm} \mathrm{a}^{-1}$ (corresponding to $8 \mathrm{~cm} \mathrm{l.w.e.).} \mathrm{This} \mathrm{means} \mathrm{that} \mathrm{the}$ snow may still experience significant temperature gradients and vapour-pressure gradients due to synoptic influences and solar heating for 2-3 years after deposition.

Further investigation into these processes would benefit from high-resolution observations of the near-surface snow and the explicit inclusion of windpumping and solar heating of snow in our model.

\section{ACKNOWLEDGEMENTS}

We thank H. Conway, J. Lundin, M. Koutnik, L. A. Rasmussen, T. Neumann, an anonymous reviewer and the University of Washington Glaciology Group for excellent comments and suggestions. We also thank the Baseline Surface Radiation
Network, E. Dutton and T. Mefford of NOAA-GMD for providing the data used in this study. This work was funded under US National Science Foundation grant Nos OPP-0540090 and OPP-0636997.

\section{REFERENCES}

Albert, M.R. and W.R. McGilvary. 1992. Thermal effects due to air flow and vapor transport in dry snow. J. Glaciol., 38(129), 273-281.

Aldaz, L. and S. Deutsch. 1967. On a relationship between air temperature and oxygen isotope ratio of snow and firn in the South Pole region. Earth Planet. Sci. Lett., 3(3), 267-274.

Bailey, D.A. and A.H. Lynch. 2000. Development of an Antarctic regional climate system model. Part II: station validation and surface energy balance. J. Climate, 13(8), 1351-1361.

Bingham, R.G., M.J. Siegert, D.A. Young and D.D. Blankenship. 2007. Organized flow from the South Pole to the Filchner-Ronne ice shelf: an assessment of balance velocities in interior East Antarctica using radio echo sounding data. J. Geophys. Res., 112(F03), F03S26. (10.1029/2006JF000556.)

Bintanja, R. 2000. The surface heat budget of Antarctic snow and blue ice: interpretation of temporal and spatial variability. J. Geophys. Res., 105(D19), 24,387-24,407.

Brandt, R.E. and S.G. Warren. 1993. Solar-heating rates and temperature profiles in Antarctic snow and ice. J. Glaciol., 39(131), 99-110.

Brandt, R.E. and S.G. Warren. 1997. Temperature measurements and heat transfer in near-surface snow at the South Pole. J. Glaciol., 43(144), 339-351.

Briegleb, B.P. and D.H. Bromwich. 1998. Polar radiation budgets of the NCAR CCM3. J. Climate, 11(6), 1246-1269.

Carroll, J.J. 1982. Long-term means and short-term variability of the surface energy balance components at the South Pole. J. Geophys. Res., 87(C6), 4277-4286.

Carslaw, H.S. and J.C. Jaeger. 1959. Conduction of heat in solids. Second edition. Oxford, Clarendon Press.

Chen, G. and 17 others. 2004. A reassessment of $\mathrm{HO}_{x}$ South Pole chemistry based on observations recorded during ISCAT 2000. Atmos. Environ., 38(32), 5451-5461.

Cheng, Y., M.B. Parlange and W. Brutsaert. 2005. Pathology of Monin-Obukhov similarity in the stable boundary layer. J. Geophys. Res., 110(D06), D06101. (10.1029/2004JD004923.)

Colbeck, S.C. 1989. Air movement in snow due to windpumping. J. Glaciol., 35(120), 209-213.

Dalrymple, P.C., H.H. Lettau and S.H. Wollaston. 1966. South Pole micrometeorology program: data analysis. In Rubin, M.J., ed. Studies in Antarctic meteorology. Washington, DC, American Geophysical Union, 13-57. (Antarctic Research Series 9.)

Davis, D. and 8 others. 2004. South Pole $\mathrm{NO}_{x}$ chemistry: an assessment of factors controlling variability and absolute levels. Atmos. Environ., 38(32), 5375-5388.

Epstein, S., R.P. Sharp and A.J. Gow. 1965. Six-year record of oxygen and hydrogen isotope variations in South Pole firn. J. Geophys. Res., 70(8), 1809-1814.

Fogt, R.L. and D.H. Bromwich. In press. Atmospheric moisture and cloud cover characteristics forecast by AMPS. Weather Forecast.

Gow, A.J. 1965. On the accumulation and seasonal stratification of snow at the South Pole. J. Glaciol., 5(40), 467-477.

Greuell, J.W. and T. Konzelmann. 1994. Numerical modeling of the energy balance and the englacial temperature of the Greenland ice sheet: calculations for the ETH-Camp location (West Greenland, 1155 m a.s.I.). Global Planet. Change, 9(1-2), 91-114.

Helmig, D., L. Ganzeveld, T. Butler and S.J. Oltmans. 2007. The role of ozone atmosphere-snow gas exchange on polar, boundarylayer tropospheric ozone - a review and sensitivity analysis. Atmos. Chem. Phys., 7(1), 15-30. 
Helsen, M.M., R.S.W. van de Wal, M.R. van den Broeke, D. van As, H.A.J. Meijer and C.H. Reijmer. 2005. Oxygen isotope variability in snow from western Dronning Maud Land, Antarctica and its relation to temperature. Tellus, 57B(5), 423-435.

Helsen, M.M. and 6 others. 2006. Modeling the isotopic composition of Antarctic snow using backward trajectories: simulation of snow pit records. J. Geophys. Res., 111(D15), D15109. (10.1029/2005JD006524.)

Hines, K.M., R.W. Grumbine, D.H. Bromwich and R.I. Cullather. 1999. Surface energy balance of the NCEP MRF and NCEPNCAR reanalysis in Antarctic latitudes during FROST. Weather Forecast., 14(6), 851-866.

Hines, K.M., D.H. Bromwich, P.J. Rasch and M.J. Iacono. 2004. Antarctic clouds and radiation within the NCAR climate models. J. Climate, 17(6), 1198-1212.

Hori, M. and 10 others. 2006. In-situ measured spectral directional emissivity of snow and ice in the 8-14 $\mu \mathrm{m}$ atmospheric window. Remote Sens. Environ., 100(4), 486-502.

Hudson, S.R. and R.E. Brandt. 2005. A look at the surface-based temperature inversion on the Antarctic plateau. J. Climate, 18(11), 1673-1696.

Hutterli, M.A., J.R. McConnell, G. Chen, R.C. Bales, D.D. Davis and D.H. Lenschow. 2004. Formaldehyde and hydrogen peroxide in air, snow and interstitial air at South Pole. Atmos. Environ., 38(32), 5439-5450.

Jackson, B.S. 1982. Surface energy budget at the South Pole during the austral summer. (Master's thesis, University of California, Davis.)

Johnsen, S.J., H.B. Clausen, K.M. Cuffey, G. Hoffmann, J. Schwander and T. Creyts. 2000. Diffusion of stable isotopes in polar firn and ice: the isotope effect in firn diffusion. In Hondoh, T., ed. Physics of ice core records. Sapporo, Hokkaido University Press, 121-140.

Jouzel, J., L. Merlivat, J.R. Petit and C. Lorius. 1983. Climatic information over the last century deduced from a detailed isotopic record in the South Pole snow. J. Geophys. Res., 88(C4), 2693-2703.

Kawamura, K. and 8 others. 2006. Convective mixing of air in firn at four polar sites. Earth Planet. Sci. Lett., 244(3-4), 672-682.

King, J.C. and W.M. Connolley. 1997. Validation of the surface energy balance over the Antarctic ice sheets in the U.K. Meteorological Office unified climate model. J. Climate, 10(6), 1273-1287.

King, J.C., P.S. Anderson, M.C. Smith and S.D. Mobbs. 1996. The surface energy and mass balance at Halley, Antarctica during winter. J. Geophys. Res., 101(D14), 19,119-19,128.

Kuhn, M., A.J. Riordan and I.A. Wagner. 1975. The climate of Plateau Station. In Weller, G. and S.A. Bowling, eds. Climate of the Arctic. Boston, MA, American Meteorological Society, 255-267.

List, R.J. 1949. Smithsonian meteorological tables. Sixth edition. Washington, DC, Smithsonian Institution Press.

Liston, G.E. and J.-G. Winther. 2005. Antarctic surface and subsurface snow and ice melt fluxes. J. Climate, 18(10), 1469-1481.

Mahrt, L. 1998. Stratified atmospheric boundary layers and breakdown of models. Theor. Comput. Fluid Dyn., 11(3-4), 263-279.

Mayewski, P.A. and 18 others. 2005. The International TransAntarctic Scientific Expedition (ITASE): an overview. Ann. Glaciol., 41, 180-185.

McConnell, J.R., R.C. Bales, R.W. Stewart, A.M. Thompson, M.R. Albert and R. Ramos. 1998. Physically based modeling of atmosphere-to-snow-to-firn transfer of $\mathrm{H}_{2} \mathrm{O}_{2}$ at South Pole. J. Geophys. Res., 103(D9), 10,561-10,570.

Morris, E.M. and D.G. Vaughan. 1994. Snow surface temperatures in West Antarctica. Antarct. Sci., 6(4), 529-535.

Mosley-Thompson, E., J.F. Paskievitch, A.J. Gow and L.G. Thompson. 1999. Late 20th century increase in South Pole snow accumulation. J. Geophys. Res., 104(D4), 3877-3886.

Neff, W. 1999. Decadal time scale trends and variability in the tropospheric circulation over the South Pole. J. Geophys. Res., 104(D22), 27,217-27,251

Neumann, T.A., E.D. Waddington, E.J. Steig and P.M. Grootes. 2005. Non-climate influences on stable isotopes at the Taylor Mouth Antarctica. J. Glaciol., 51(173), 248-258.

Pahlow, M., M.B. Parlange and F. Porté-Agel. 2001. On MoninObukhov similarity In the stable atmospheric boundary layer. Bound.-Layer Meteorol., 99(2), 225-248.

Patankar, S.V. 1980. Numerical heat transfer and fluid flow. New York, Hemisphere Publishing

Reijmer, C.H. and J. Oerlemans. 2002. Temporal and spatial variability of the surface energy balance in Dronning Maud Land East Antarctica. J. Geophys. Res., 107(D24), 4759-4770.

Schwerdtfeger, W. 1970. The climate of the Antarctic. In Orvig, S., ed. Climates of the polar regions. New York, Elsevier, 253-355. (World Survey of Climatology 14.)

Schwerdtfeger, W. 1984. Weather and climate of the Antarctic. Amsterdam, Elsevier.

Simmonds, I., K. Keay and E.-P. Lim. 2003. Synoptic activity in the seas around Antarctica. Mon. Weather Rev., 131(2), 272-288.

Stauffer, B., J. Flückiger, E.W. Wolff and P.R.F. Barnes. 2004 The EPICA deep ice cores: first results and perspectives. Ann. Glaciol., 39, 93-100.

Town, M.S. 2007. Investigations into the climate of the South Pole. (PhD thesis, University of Washington.)

Town, M.S., V.P. Walden and S.G. Warren. 2005. Spectral and broadband longwave downwelling radiative fluxes, cloud radiative forcing, and fractional cloud cover over the South Pole. J. Climate, 18(20), 4235-4252.

Town, M.S., V.P. Walden and S.G. Warren. 2007. Cloud cover over the South Pole from visual observations, satellite retrievals, and surface-based infrared radiation measurements. J. Climate, 20(3), 544-559.

Trenberth, K.E. 1983. What are the seasons? Bull. Am. Meteorol. Soc., 64(11), 1276-1282.

Trenberth, K.E. and A. Solomon. 1994. The global heat balance: heat transports in the atmosphere and ocean. Climate Dyn., 10(3), 107-134.

Van As, D., M.R. van den Broeke and R.S.W. van de Wal. 2005. Daily cycle of the surface energy balance on the high Antarctic plateau. Antarct. Sci., 17(1), 121-133.

Van den Broeke, M.R., C.H. Reijmer, D. van As, R.S.W. van de Wal and J. Oerlemans. 2005. Seasonal cycles of Antarctic surface energy balance from automatic weather stations. Ann. Glaciol., 41, 131-139.

Van den Broeke, M., C. Reijmer, D. van As and W. Boot. 2006. Daily cycle of the surface energy balance in Antarctica and the influence of clouds. Int. J. Climatol., 26(12), 1587-1605.

Warren, S.G. 1982. Optical properties of snow. Rev. Geophys. Space Phys., 20(1), 67-89.

Warren, S.G. 1996. Antarctica. In Schneider, S.H., ed. Encyclopedia of climate and weather. Vol. 1. New York, Oxford University Press, 31-39. 